\title{
A New Operative Fiberpyeloscope
}

\author{
Seigi Tsuchida \\ Department of Urology, Akita University School of Medicine, \\ Akita
}

Tsuchida, S. A New Operative Fiberpyeloscope. Tohoku J. exp. Med., 1975, 116 (4), 369-372, — Operative pyeloscopes developed up to now have been of limited effectivness because of an inadequate visual field and difficulties in handling procedure. The author has made up a flexible fiber pyeloscope with which it is possible to extract renal pelvic and caliceal stones easily. This pyeloscope has the following specifications: effective length, $630 \mathrm{~mm}$; diameter, $8.5 \mathrm{~mm}$; field of vision, $60^{\circ}$. In addition, the tip of the scope can be deflected $90^{\circ}$ up or down from the basic position with a hand manipulated angle deflector knob on the scope grip. This allows the inside of the renal pelvis to be observed clearly from every direction. Through the channel of the scope, specially designed stone grasping forceps can be inserted into the renal pelvis, and it is possible to grasp renal pelvic stones under direct observation. The fiberpyeloscope has been used in 2 cases of renal pevlic stones, in which the pelvis was exposed by subcostal flank incision. The stones were successfully extracted with the scope which was introduced through a small incision on the renal perlis.

operative pyeloscope; endoscopic removal of renal calculi

Rupell and Brown (1941) first observed the renal pelvis and calix endoscopically during surgical operation. They introduced a panendoscope through the nephrosotomy catheter, and extracted renal pelvic stones with the biopsy forceps. Since then, various types of endoscope have been manufactured for the observation of renal stones, and filling defects within the pelvis and calix. Unfortunately, however, little evaluation has been made of these endoscopes. With a newly designed flexible fiberscope, we (Tsuchida and Sugawara 1973) succeeded in observing the urinary bladder neck. In order to provide for easier handling of the fiberscope, we further made an improved operative pyeloscope, shortened in total length and with an inner channel for the passage of three-hook stone grasping forceps. This is a preliminary report on the construction of the new fiberscope and its clinical use.

\section{Description of Instrument and Technique}

As shown in Fig. la and b, the total length of the fiberscope is $410 \mathrm{~mm}$ (not including the grip). The outer diameter is $8.5 \mathrm{~mm}$. The optical system is fixed focus with a visual field of $60^{\circ}$, and the observation direction is forward. This fiberscope has a remote illuminating system with a glass fiber bundle. The fiberpyeloscope consists of a grip for controlling the instrument, a rigid part, a flexible part, an apical objective lens system, and

Received for publication, May 12, 1975. 
a universal cord. The length of the grip is $220 \mathrm{~mm}$. The eyepiece has an eye-sight adjuster ring, and by turning this ring, objects located at 5 to $80 \mathrm{~mm}$ distance from the objective lens become clearly visible. Down from this ring, there is an angle deflector knob which controls the degree of deflection of the scope tip. The channel for fluid/air passage is $1.5 \mathrm{~mm}$ in inner diameter. Through this channel, the washing solution can be sent into the renal pelvis, and at the same time can be cycled.

The forceps channel has an inner diameter of $2.5 \mathrm{~mm}$ ald is built into the scope so as to provide for various manipulations of the forceps. The rigid part is covered by a metal sheath of $300 \mathrm{~mm}$ length, and can be held with the left hand for easy maneuvering of the scope in endoscopy. The flexible part is $90 \mathrm{~mm}$ in length and is covered by a Desmopan tube to allow smooth introduction into the renal pelvis. The length of $30 \mathrm{~mm}$ at the apex of the flexible part is controlled by the angle knob, and can be moved by $90^{\circ}$ in the left and right direction, a total of $180^{\circ}$, by hand manipulation. The apex of the scope is made of metal, and is smooth enough not to damage the mucosa during the introduction

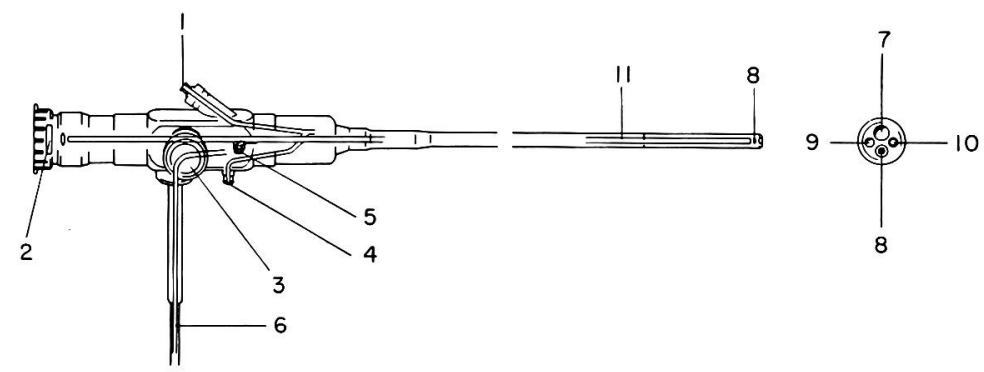

Fig. 1a

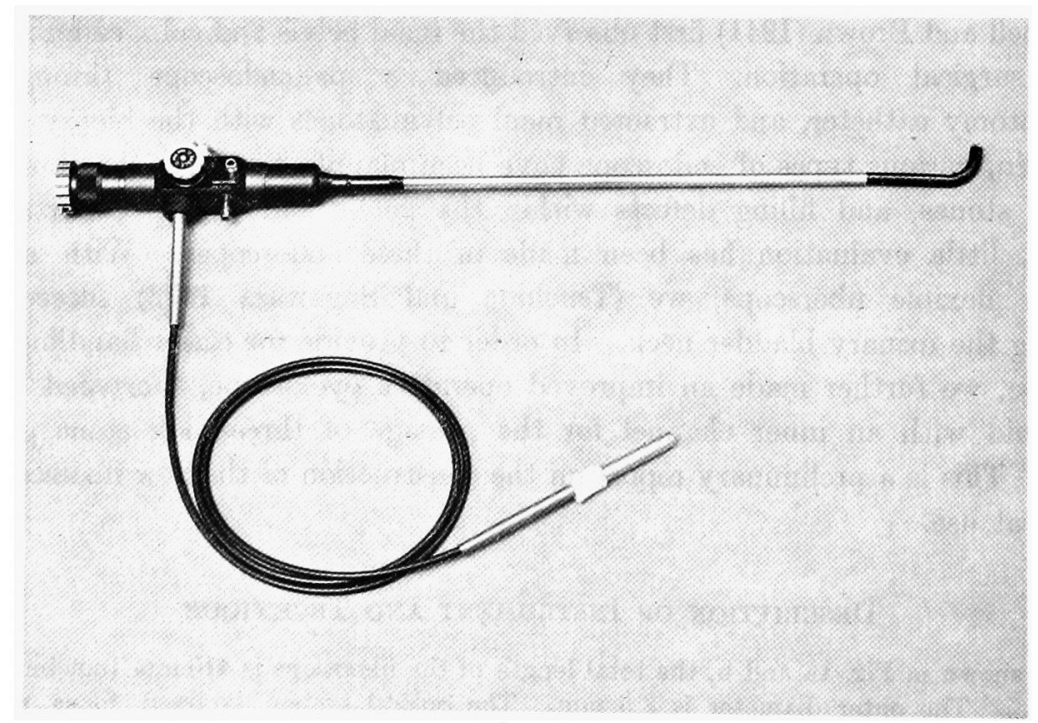

Fig. 1b

Fig. 1. a: Schematic illustration of flexible fiberpyeloscope.

1) biopsy forceps inlet, 2) eyepiece lens, 3) angle deflector, up and down,

4) suction outlet, 5) fluid/air inlet, 6) light guide cable, 7) forceps outlet, 8) objective lens, 9) fluid/air outlet, 10) light guide illumination, 11) image bundle.

b: Complete fiberscope unit. 


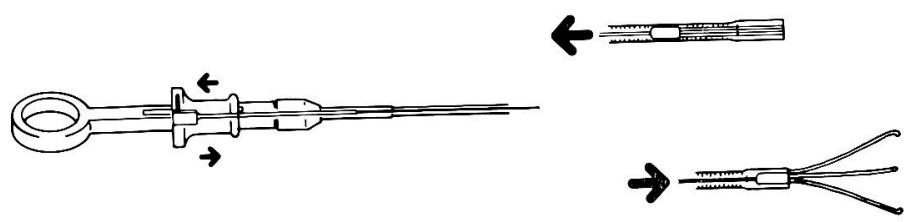

Fig. 2a

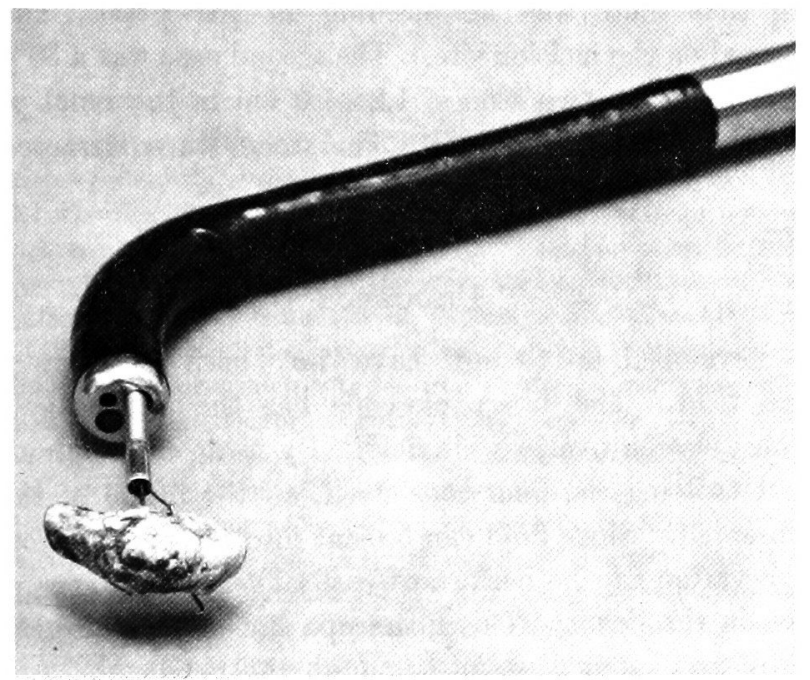

Fig. 2b

Fig. 2. a: Schematic illustration of three-hook stone grasping forceps. b: The forceps catching a stone.

procedure into the renal pelvis. In this part, there are built-in fluid/air outlets, an illumination outlet and an objective lens system. The light conducting fiber bundle and the photographic circuit are built into the universal cord, and Xenon lamp is used to supply light.

Fig. 2a shows the construction of the three-hook stone grasping forceps. The three hooks are pushed out or withdrawn into the compartment by manipulation of the handle. With this forceps, stones from 2 to $20 \mathrm{~mm}$ in diameter can be easily grasped without fail. The action of the forceps in catching a stone can be seen in Fig. 2 b.

The operation procedure is as follows: First, the flexible pyeloscope is sterilized with ethylene oxide gas. The renal pelvis is exposed operatively by standard subcostal flank incision. A small incision is made on the renal pelvis, through which the pyeloscope is introduced. The next step is to send normal saline into the pelvis to expand it a little. Observation of the renal pelvis and the calix is carried out systematically, making use of angle deflection at the scope tip. If a stone is found, the three-hook forceps is pushed out from the scope tip, and the three hooks are opend by pulling the handle of the forceps to grasp the stone. After confirming that the stone has been grasped tightly, the scope can be taken out with the three hook forceps from the incision site. 


\section{Clinical Results}

We have tried this operative pyeloscope on two cases of renal pelvic stone. The pyelo-ureteral part was adequately exposed with a subcostal flank incision and additional renal mobilization was unnecessary. The first case was a 32 year-old male. X-ray examination revealed a solitary renal pelvic stone of $1.5 \times 1.0 \mathrm{~cm}$. A $1 \mathrm{~cm}$ incision was made on the renal pelvis for the introduction of the fiberscope, and the stone was extracted under direct observation using the three-hook forceps. After confirming that there was no bleeding in the pelvis, an uninterrupted suture was performed on the incision site. The second case was a 30 year-old female. $\mathrm{X}$-ray examination revealed two stones, $1.2 \times 1.0 \mathrm{~cm}$ in the renal pelvis and $0.5 \times$ $0.5 \mathrm{~cm}$ in the calix at the superior pole. The stones were extracted easily by the same method.

\section{Discussion}

Pyeloscopes developed up to now have not been effective because of an inadequate visual field. The fiberpyeloscope has the advantage over them in providing clear observation over a wide field. By using the angle deflection of $90^{\circ}$ up and down and twisting the fiberscope itself, all the inside of the pelvis can be systematically observed. Since fluid can be sent into the pelvis through the channel of the scope, observation can be performed easily even when there is bleeding from an ulcerous lesion in the pelvis. This fiberscope can also be effectively applied for the examination of suspicious cases of tumor in the pelvis.

\section{References}

1) Rupell, E. \& Brown, R. (1941) Nephroscopy with removal of stone following nephrostomy for obstructive calculous anuria. $J$. Urol., 46, 177-182.

2) Tsuchida, S. \& Sugawara, H. (1973) A new flexible fibercystoscope for visualization of the bladder neck. $J$. Urol., 109, 830-831. 